\title{
Analisis Heat /sland pada Perkebunan Kelapa Sawit: Studi Kasus di Kabupaten Kayong Utara, Kalimantan Barat
}

\author{
Nurul Ihsan Fawzi ${ }^{1}$ \\ Alam Sehat Lestari, Sukadana, Kalimantan Barat, Indonesia \\ Marindah Yulia Iswari \\ Lembaga IImu Pengetahuan Indonesia, Jakarta, Indonesia
}

Artikel Masuk : 12 September 2019

Artikel Diterima : 1 April 2020

Tersedia Online : 31 Agustus 2020

\begin{abstract}
Abstrak: Selama rentang tahun 2000 - 2017, 3,06 juta hektar hutan primer di Kalimantan telah dikonversi menjadi perkebunan kelapa sawit. Salah satu dampak dari perubahan tersebut adalah perubahan iklim lokal. Penelitian ini bertujuan untuk menganalisis heat island yang terbentuk dari perkebuan kelapa sawit. Metode analisis menggunakan estimasi suhu permukaan melalui penginderaan jauh dan zonal statistic. Data penginderaan jauh yang digunakan adalah citra Landsat 8 dengan perekaman pada tanggal 15 Juli 2018 dan 3 Agustus 2019. Hasil penelitian menunjukkan bahwa perkebunan kelapa sawit muda memiliki nilai $\mathrm{I}_{\mathrm{HI}}$ rata-rata $2,1 \pm 1,7{ }^{\circ} \mathrm{C}$ di tahun 2018 dan $1,7 \pm 1,4{ }^{\circ} \mathrm{C}$ di tahun 2019. Nilai $\mathrm{I}_{\mathrm{HI}}$ tersebut mendekati heat island pada kawasan permukiman. $\mathrm{I}_{\mathrm{HI}}$ pada perkebunan kelapa sawit yang tua (11-12 tahun) membentuk cool island dengan intensitas mendekati nilai hutan sekunder. Penurunan nilai $\mathrm{I}_{\mathrm{HI}}$ tahun 2018 dan 2019 pada perkebunan kelapa sawit disebabkan oleh pertumbuhan kelapa sawit yang menurunkan suhu permukaan. Implikasi penelitian ini adalah dapat mengetahui heat island akibat deforestasi atau perubahan tutupan lahan, terutama pada perkebunan kelapa sawit.
\end{abstract}

Kata Kunci: heat island, landsat 8; penginderaan jauh; perkebunan kelapa sawit

\begin{abstract}
Between 2000 - 2017, 3.06 million hectares of primary forest in Kalimantan have been converted into palm oil plantation. This change impacts local climate changes. This study aims is to analyze the heat island in palm oil plantation. The analytical method used surface temperature estimation through remote sensing and zonal statistics. The remote sensing data that are used is Landsat 8 images acquired on 15 July 2018 and 3 August 2019. From this research, we found that young palm oil plantations have an average $I_{H I}$ value of 2.1 $\pm 1.7^{\circ} \mathrm{C}$ in 2018 and $1.7 \pm 1.4^{\circ} \mathrm{C}$ in 2019 . The $I_{H I}$ value is close to the heat island in a built-up area. $I_{H I}$ for mature palm oil plantation (11-12 years) created a cool island with an intensity close to secondary forest. The decreasing value of IHI for 2018 and 2019 in palm oil plantations is due to the growth of palm oil trees, which decreases surface temperature. The implication of this research is to know heat island effect due to deforestation or land cover changes, especially change into palm oil plantations.
\end{abstract}

Keywords: heat island; landsat 8; palm oil plantations; remote sensing

\footnotetext{
${ }^{1}$ Korespondensi Penulis: Alam Sehat Lestari, Sukadana, Kalimantan Barat, Indonesia

Email: nurul.ihsan.f@mail.ugm.ac.id
} 


\section{Pendahuluan}

Produksi kelapa sawit di Indonesia tahun 2019 diperkirakan mencapai 43 juta ton, meningkat 1,5 juta ton dari tahun 2018 (USDA, 2019). Produksi tersebut berkontribusi terhadap 56,7\% dari total produksi global. Sebanyak 30 juta ton produksi kelapa sawit Indonesia untuk diekspor, sedangkan sisanya untuk memenuhi kebutuhan domestik dalam negeri. Ekspor kelapa sawit yang tinggi berdasar pada industri yang memerlukan minyak kelapa sawit berupa crude palm oil (CPO) dan palm kernel menjadi bahan dasar produk. Beberapa produk rumah tangga memerlukan kelapa sawit untuk membuatnya, seperti alat kosmetik, sabun, sampo, mentega, mie instan, coklat, dan minyak goreng. Kebutuhan akan minyak sawit hampir tidak dapat digantikan oleh produk lainnya sehingga kebutuhan akan kelapa sawit akan tetap tinggi.

Implikasi dari tingginya produksi kelapa sawit tersebut adalah konversi hutan primer menjadi perkebunan kelapa sawit. Selama rentang tahun $2000-2017$, 3,06 juta hektar hutan primer di Kalimantan telah dikonversi menjadi perkebunan kelapa sawit (Gaveau et al., 2019). Laporan dari USDA (2019), total lahan produksi kelapa sawit di Indonesia saat ini adalah 11,75 juta hektar. Rencana pemerintah meningkatkan penggunaan biodiesel dari B20 menjadi B30, akan berimplikasi peningkatan permintaan produksi dan upaya pemenuhannya. Peluang pembukaan hutan baru untuk untuk memenuhi kebutuhan pasar menimbulkan isu-isu lingkungan yang harus diperhatikan.

Mengukur dampak lingkungan dari konversi hutan menjadi perkebunan kelapa sawit perlu untuk dilakukan. Beberapa parameter yang dapat dilakukan adalah perubahan keanekaragaman hayati dan perubahan iklim lokal. Perubahan iklim lokal ditandai dengan peningkatan suhu lokal pada area tertentu di Bumi (Cai et al., 2018). Salah satu indikator perubahan iklim lokal adalah terbentuknya heat island. Heat island merupakan terminologi suatu area yang lebih panas dari sekitarnya. Kondisi lingkungan yang lebih panas memberi dampat negatif terhadap kesehatan (Gronlund, 2014). Urban heat island adalah contoh yang paling nyata dari perubahan tutupan lahan di kawasan perkotaan terhadap suhu permukaan (Li et al., 2018). Heat island dapat terjadi tidak hanya di perkotaan, beberapa penelitian menemukan heat island dapat terjadi juga di kawasan tambang batu bara dan perkebunan (Fawzi \& Jatmiko, 2015; Risdiyanto et al., 2019; Wang et al., 2009). Penelitian tentang heat island dapat digunakan untuk mengetahui suhu yang nyaman untuk manusia. Persepsi suhu yang nyaman di Indonesia berkisar antara 27 - 28 ${ }^{\circ} \mathrm{C}$ (Karyono, 2015). Sedangkan untuk kawasan perkotaan, suhu nyaman berkisar di suhu $30^{\circ} \mathrm{C}$ (Qaid et al., 2016). Kawasan yang melebihi suhu nyaman akan memengaruhi aktivitas dan kesehatan.

Penelitian tentang heat island yang berhubungan dengan ekspansi perkebunan kelapa sawit masih berfokus untuk melihat perubahan suhu permukaan yang diakibatkan konversi menjadi perkebunan kelapa sawit. Ramdani et al. (2014) menemukan perbedaan suhu antara hutan dan kelapa sawit muda (3 - 9 tahun) di perkebunan mencapai $4{ }^{\circ} \mathrm{C}$. Perbedaan antara hutan dan perkebunan kelapa sawit yang dewasa (10 - 20 tahun) adalah lebih rendah berkisar $1^{\circ} \mathrm{C}$. Dari hasil regresi, suhu permukaan perkebunan kelapa sawit akan sama dengan hutan jika mencapai umur 24 tahun (Rushayati et al., 2017). Akan tetapi, hal tersebut tidak bisa menggantikan keanekaragaman hayati yang hilang akibat konversi menjadi kebun monokultur (Wilcove \& Koh, 2010). Ekspansi perkebunan kelapa sawit juga meningkatkan suhu permukaan mencapai $6,5^{\circ} \mathrm{C}$ (Hardwick et al., 2015) hingga $10,1^{\circ} \mathrm{C}$ (Sabajo et al., 2017).

Penelitian-penelitian yang telah dilakukan sebelumnya hanya menjelaskan tentang suhu yang lebih tinggi pada area perkebunan kelapa sawit. Tidak ada hasil yg menjelaskan distribusi peningkatan suhu dan analisis tentang heat island. Mengetahui intensitas heat island yang terjadi menjadi faktor penting untuk menilai pola iklim lokal yang terbentuk. Hal yang menarik di sini adalah heat island yang sebagian besar dikaji merupakan dampak dari perubahan lahan di perkotaan yang terjadi oleh adanya urbanisasi (Li et al., 2018; Yang et al., 2019). Namun pada penelitian ini, perubahan lahan difokuskan pada deforestasi dan 
pembukaan lahan untuk perkebunan kelapa sawit. Analisis heat island paling ideal dilakukan dengan teknik penginderaan jauh (Zhou et al., 2018). Metode ini efektif dari segi waktu dan biaya. Penelitian ini bertujuan untuk menganalisis heat island yang terbentuk dari perkebunan kelapa sawit. Heat island yang dianalisis adalah heat island permukaan (Rasul et al., 2017).

\section{Metode Penelitian}

\section{Lokasi Penelitian}

Penelitian ini dilakukan di Kabupaten Kayong Utara, Kalimantan Barat (Gambar 1). Fokus analisis di Kecamatan Sukadana dan Kecamatan Simpang Hilir. Fokus lokasi ini dipilih berdasarkan ketersediaan data yang bebas awan dan heterogenitas tutupan lahan. Terdapat hutan primer, perkebunan kelapa sawit, area permukiman dan lahan pertanian. Jumlah penduduk di dua kecamatan tersebut adalah 26.533 jiwa (BPS Kab. Kayong Utara, 2018). Jumlah produksi kelapa sawit di Kabupaten Kayong Utara adalah 51.871 ton (BPS Kab. Kayong Utara, 2019). Perkebunan kelapa sawit di Kecamatan Simpang Hilir menyumbang 93,91\% dari keseluruhan produksi dengan luas total area 17.025 hektar.
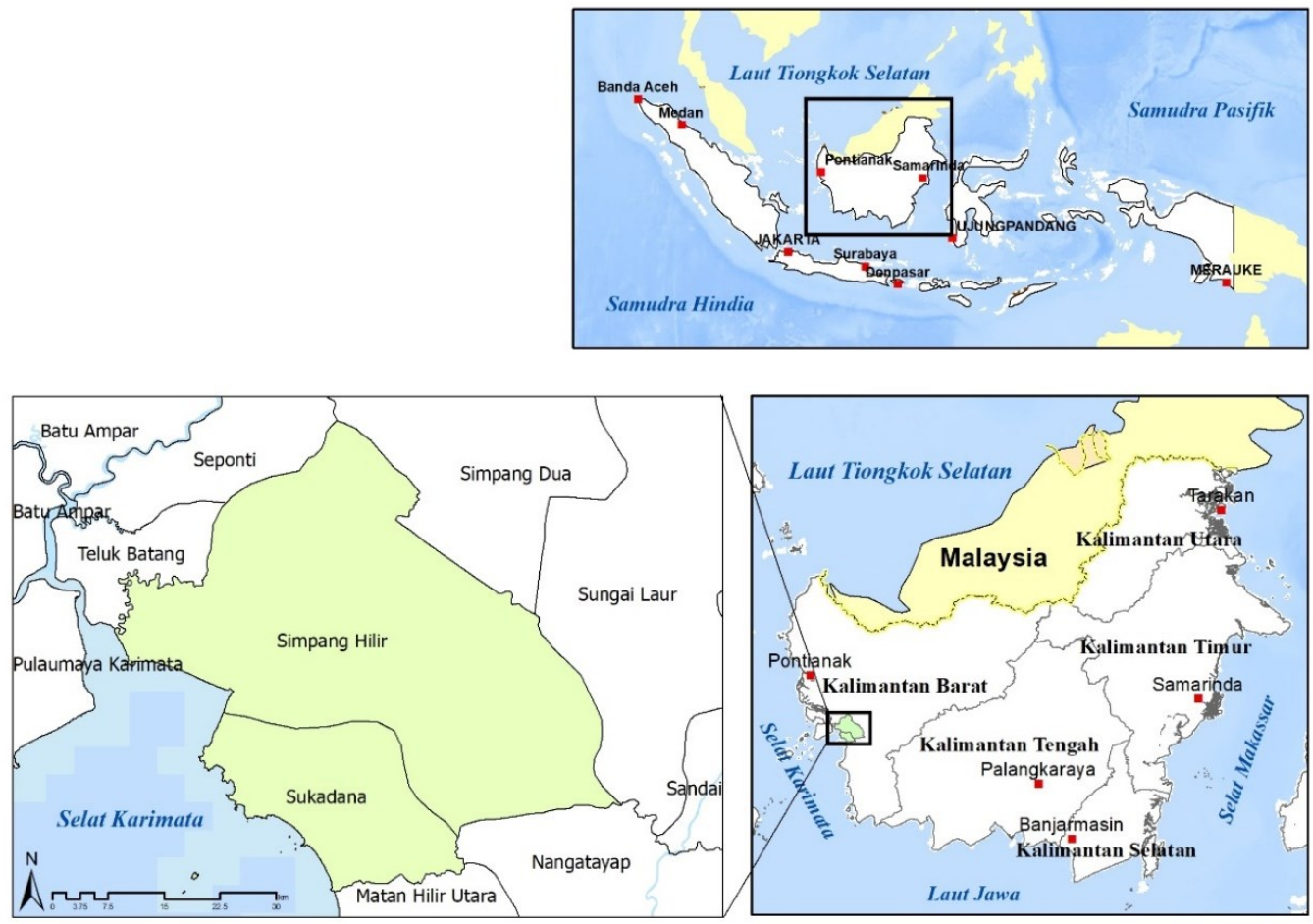

\section{Gambar 1. Lokasi Penelitian di Kecamatan Sukadana dan Kecamatan Simpang Hilir, Kabupaten Kayong Utara}

\section{Data dan Analisis}

Data penginderaan jauh yang digunakan adalah citra Landsat 8. Path/row yang digunakan adalah 121/59 perekaman tanggal 15 Juli 2018 dan 3 Agustus 2019. Citra telah terkoreksi level Tier 1 (T1) dengan datum WGS 1984. Landsat T1 telah terkoreksi geometrik (L1TP) dan terkalibrasi sehingga dapat digunakan untuk analisis multitemporal. 
Kesalahan hasil koreksi (root mean square error/RMSE) yang ditoleransi adalah $\leqq 12$ meter (USGS, 2019).

Informasi tentang tutupan lahan diperoleh dengan interpretasi visual. Interpretasi visual dilakukan untuk mendapatkan data yang lebih kompleks dan untuk menghindari kesalahan klasifikasi. Terdapat sepuluh kelas tutupan lahan yang diperoleh dalam interpretasi: (1) hutan montana; (2) hutan primer; (3) hutan sekunder; (4) hutan mangrove; (5) permukiman; (6) kebun masyarakat; (7) sawah dan perladangan; (8) kebun kelapa sawit muda (3-9 tahun); (9) kebun kelapa sawit tua (10 - 20 tahun); (10) semak atau lahan terbuka; dan (11) awan. Definisi hutan montana adalah hutan tropis yang berada di wilayah pegunungan. Jenis pohon dan kanopi berbeda dengan pohon di hutan dataran rendah atau rawa. Hutan primer adalah hutan yang belum terjadi aktivitas pembalakan liar (illegal logging) dengan tutupan kanopi $>90 \%$. Hutan sekunder adalah hutan yang telah terdegradasi atau rusak, namun mengalami regenerasi kembali secara alami ataupun dibantu oleh manusia. Kebun masyarakat adalah lahan yang telah diolah untuk kebun oleh masyarakat (Salafsky, 1994). Jenis tanaman dalam kebun tersebut adalah durian, jengkol, dan jenis buah-buahan lainnya. Seringkali pada bawah kanopi ditanam pisang atau tanaman holtikultura.

Perolehan suhu permukaan menggunakan citra Landsat 8 melalui beberapa tahap pemrosesan. Tahapan tersebut adalah: (1) perolehan emisivitas objek menggunakan indeks vegetasi (Fawzi, 2014; Valor \& Caselles, 1996). Dalam koreksi ini band citra Landsat 8 yang digunakan adalah band 4 (merah) dan 5 (inframerah dekat). (2) Koreksi atmosfer $\left(\mathrm{L}_{\text {sensor, }, \lambda}\right)$ untuk menghitung pengaruh radiasi upwelling $\left(\mathrm{L}_{\mathrm{atm}}^{\downarrow}\right)$, downwelling $\left(\mathrm{L}_{\mathrm{atm}}^{\uparrow}\right)$, dan atmospheric transmission $\left(\tau_{\lambda}\right)$. Persamaan untuk koreksi menggunakan Coll et al. (2010) dengan parameter atmosfer diperoleh dari Barsi (2019). Data yang digunakan adalah band 10 yang telah terkoreksi radian $\left(\mathrm{L}_{\lambda}\right)$, emisivitas objek $(\varepsilon)$, dan $\mathrm{L}_{\mathrm{atm}}^{\downarrow}, \mathrm{L}_{\mathrm{atm}}^{\uparrow}$, dan $\tau_{\lambda}$. (3) Perolehan suhu permukaan $\left(\mathrm{T}_{\mathrm{rad}}\right)$ menggunakan persamaan USGS (2019), dengan data yang digunakan adalah $\mathrm{L}_{\text {sensor, } \lambda}$. Nilai konstanta $\mathrm{K} 1=774,8853$ dan $\mathrm{K} 2=1321,0789$ yang diperoleh dari metadata citra.

Nilai ambang batas untuk deteksi heat island diperoleh dengan persamaan (1), sebagai berikut:

$$
\Delta \mathrm{T}=\mu+0,5 \alpha
$$

$\mu$ adalah nilai rata-rata suhu permukaan dan $\alpha$ adalah standar deviasi dari wilayah penelitian. Intensitas heat island diperoleh dengan persamaan yang dikemukakan oleh Lima Alves and Lopes (2017); Ozdemir et al. (2012), seperti yang ditampilkan pada persamaan (2) sebagai berikut:

$$
\mathrm{I}_{\mathrm{HI}}=\mathrm{T}_{\mathrm{rad}}-\Delta \mathrm{T}
$$

Metode zonal statictic diterapkan untuk mengetahui nilai suhu permukaan dan intensitas heat island pada setiap tipe tutupan lahan. Metode ini menghitung nilai-nilai raster dalam zona yang ditentukan oleh dataset lain (ESRI, 2016).

\section{Hasil dan Pembahasan}

Hasil pengolahan data disajikan pada Tabel 1 dan Gambar 2. Secara teori, hutan primer dengan kepadatan pohon lebih tinggi memiliki suhu permukaan lebih rendah dari hutan sekunder. Berdasarkan hasil analisis, perbedaan suhu permukaan antara hutan primer dan hutan sekunder hanya $0.5^{\circ} \mathrm{C}$. Suhu yang terekam oleh satelit adalah suhu dari atas kanopi hutan yang sama berupa vegetasi. Nilai suhu permukaan ini tidak mencerminkan suhu udara di dalam hutan, yang tentu saja ada perbedaan yang cukup jelas antara hutan primer dan sekunder. Pada suhu hutan primer dan permukiman, terdapat perbedaan $3,5^{\circ} \mathrm{C}$ di tahun 2018 dan $4,6^{\circ} \mathrm{C}$ di tahun 2019. Hal ini disebabkan oleh lahan 
terbangun dengan kapasitas termal yang tinggi menyebabkan suhu lebih tinggi dari area bervegetasi.

Tabel 1. Statistik Hasil Pengolahan Citra Satelit Tahun 2018 dan 2019

\begin{tabular}{|c|c|c|c|c|c|c|c|c|c|}
\hline & \multirow{2}{*}{ Tutupan Lahan } & \multicolumn{2}{|c|}{$\begin{array}{c}\text { Suhu rerata } \\
\left({ }^{\circ} \mathbf{C}\right)\end{array}$} & \multicolumn{2}{|c|}{$\begin{array}{l}\text { SD } \\
\left({ }^{\circ} \mathrm{C}\right)\end{array}$} & \multicolumn{2}{|c|}{$\begin{array}{c}\text { Suhu min } \\
\left({ }^{\circ} \mathrm{C}\right)\end{array}$} & \multicolumn{2}{|c|}{$\begin{array}{l}\text { Suhu maks } \\
\left({ }^{\circ} \mathrm{C}\right)\end{array}$} \\
\hline & & 2018 & 2019 & 2018 & 2019 & 2018 & 2019 & 2018 & 2019 \\
\hline 1 & Hutan montana & 28.4 & 25.9 & 2.1 & 1.3 & 17.2 & 20.8 & 32.5 & 29.9 \\
\hline 2 & Hutan primer & 30.7 & 27.6 & 1.3 & 0.7 & 19.8 & 21.5 & 37.1 & 36.4 \\
\hline 3 & Hutan sekunder & 30.4 & 28.2 & 2.5 & 0.81 & 18.5 & 25.8 & 39.4 & 36.7 \\
\hline 4 & Hutan mangrove & 32.5 & 29.9 & 2.5 & 0.8 & 24.5 & 27.0 & 37.9 & 35.1 \\
\hline 5 & Permukiman & 34.2 & 32.2 & 2.5 & 1.52 & 26.2 & 26.1 & 42.6 & 37.6 \\
\hline 6 & Kebun masyarakat & 33.5 & 29.9 & 1.8 & 1.1 & 27.6 & 24.7 & 42.8 & 37.2 \\
\hline 7 & Sawah dan perladangan & 33.9 & 30.7 & 2.0 & 1.8 & 26.5 & 26.4 & 44.0 & 45.6 \\
\hline 8 & Kebun kelapa sawit muda & 34.8 & 30.3 & 1.7 & 1.4 & 26.4 & 24.7 & 44.0 & 38.3 \\
\hline 9 & Kebun kelapa sawit tua & 32.0 & 28.0 & 1.0 & 0.9 & 28.8 & 23.7 & 41.0 & 35.8 \\
\hline 10 & Semak atau lahan terbuka & 32.3 & 29.6 & 2.3 & 1.6 & 22.1 & 23.9 & 41.0 & 40.6 \\
\hline 11 & Awan & 23.1 & 25.3 & 4.6 & 2.0 & 9.0 & 16.5 & 36.1 & 32.9 \\
\hline
\end{tabular}

Deforestasi yang terjadi di Taman Nasional Gunung Palung, menyebabkan hutan terkonversi menjadi semak-semak atau lahan terbuka (Curran et al., 2004; Fawzi et al., 2019; Fawzi et al., 2018). Perbedaan suhu permukaan dengan hutan primer untuk area adalah $1,5^{\circ} \mathrm{C}$ di tahun 2018 dan $2^{\circ} \mathrm{C}$ di tahun 2019 . Suhu permukaan pada area semak atau lahan terbuka lebih rendah dari suhu area permukiman, walaupun lebih tinggi dari hutan primer. Perbedaan suhu untuk area kebun masyarakat dengan hutan primer adalah $2,8^{\circ} \mathrm{C}$ di tahun 2018 dan $2,3^{\circ} \mathrm{C}$ di tahun 2019. Terdapat perbedaan suhu antara kebun kelapa sawit muda dan kebun kelapa sawit tua. Rata-rata suhu permukaan kebun kelapa sawit muda adalah $34,8^{\circ} \mathrm{C}$ di tahun 2018 dan $30,3^{\circ} \mathrm{C}$ di tahun 2019. Pola penurunan suhu ini terjadi untuk suhu di 2019 karena ada faktor peningkatan aerosol di atmosfer, jika dilihat dengan beda suhu dengan hutan primer, kebun kelapa sawit muda memiliki beda suhu $4,1^{\circ} \mathrm{C}$ di tahun 2018 dan $\sim 3^{\circ} \mathrm{C}$ di tahun 2019. Perkebunan kelapa sawit yang masih muda, dimulai dengan pembukaan lahan dan penanaman pada rentang waktu 2011 - 2013 (umur 6-8 tahun). Sedangkan untuk kebun kelapa sawit tua, mulai penanaman dimulai tahun 20072008 (umur $11-12$ tahun). Rata-rata suhu permukaannya adalah $32^{\circ} \mathrm{C}$ di tahun 2018 dan $28^{\circ} \mathrm{C}$ di tahun 2019. Beda dengan hutan primer lebih rendah dengan kelapa sawit muda, yaitu $1,3^{\circ} \mathrm{C}$ di tahun 2018 dan $0,4^{\circ} \mathrm{C}$ di tahun 2019. Suhu ini hampir menyamai suhu hutan primer. Dari sini dapat disimpulkan bahwa suhu permukaan tahun 2019 memiliki statistik lebih rendah dari tahun 2018. Namun, perbedaan-perbedaan suhu antara tutupan lahan memiliki pola yang sama.

Perhitungan heat island menggunakan nilai $\mu$ (rata-rata) dan $\alpha$ (standar deviasi) dari citra suhu permukaan. Hasil untuk tahun $2018, \mu=31,28^{\circ} \mathrm{C}$ dan nilai $\alpha=1,42^{\circ} \mathrm{C}$, nilai ambang batas untuk $\Delta \mathrm{T}_{2018}$ adalah $32,7^{\circ} \mathrm{C}$, sedangkan untuk tahun $2019 \mu=28,41^{\circ} \mathrm{C}$ dan nilai $\alpha=1,88^{\circ} \mathrm{C}$, nilai ambang batas untuk $\Delta \mathrm{T}_{2019}$ adalah $29.35^{\circ} \mathrm{C}$. Tabel 1 juga menjelaskan bahwa nilai suhu rata-rata tahun 2018 lebih tinggi dari tahun 2019. Hal ini dikarenakan oleh adanya kebakaran hutan yang melanda Kalimantan Barat pada tahun 2019. KLHK (2019) melaporkan, sampai dengan Juni dan Juli 2019 telah terjadi kebakaran hutan dan lahan di Provinsi Kalimantan Barat seluas 3.315 Hektar. Tercatat dari pantauan citra satelit LAPAN bahwa jumlah titik hotspot di Kalimantan Barat yang terekam selama tahun 2019 sejumlah 28.722 titik. Sejumlah 11.615 titik mempunyai suhu $\geq 80 \%$ yang mengindikasikan adanya kebakaran pada lokasi tersebut. Akumulasi partikel aerosol dari asap kebakaran hutan yang 
terjadi ini memengaruhi suhu di lokasi kebakaran tersebut (NASA, 2019). Asap yang dibentuk dari kebakaran pada tahun 2018 akan tersisa pada tahun 2019. Keberadaan partikel tersebut dapat menurunkan suhu permukaan, walaupun dalam visual citra kondisi bagus dan tanpa awan (Robock, 1991). Faktor yang berpengaruh adalah peningkatan hambatan transmisi gelombang elektromagnetik di atmosfer $\left(\tau_{\lambda 2019}=0,48\right)$.

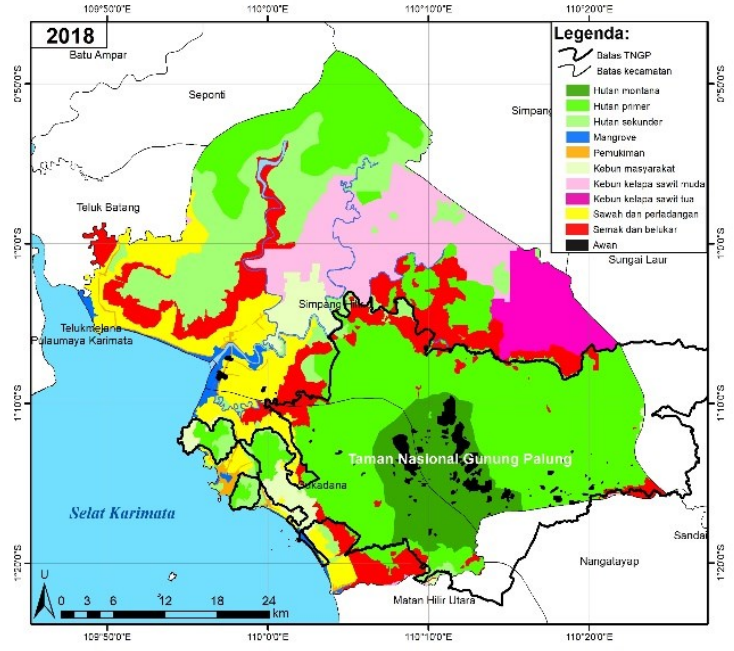

(a)

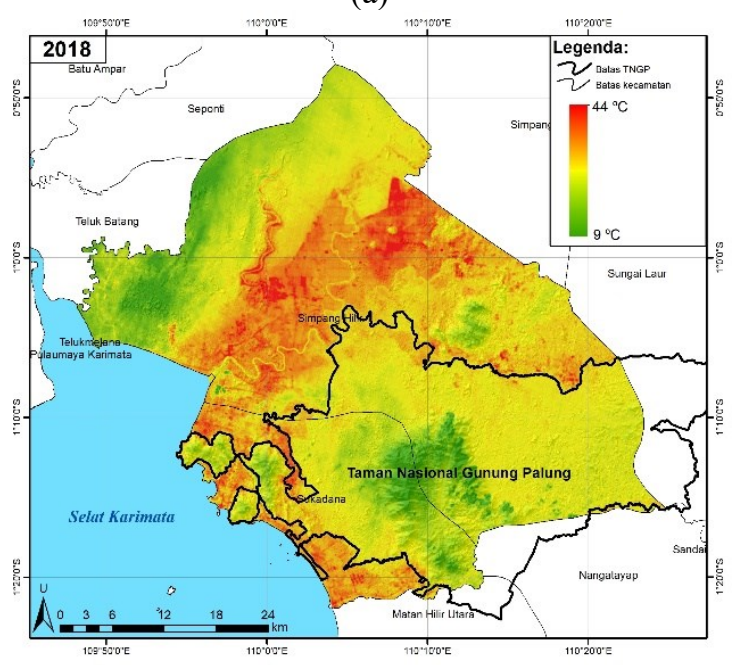

(c)

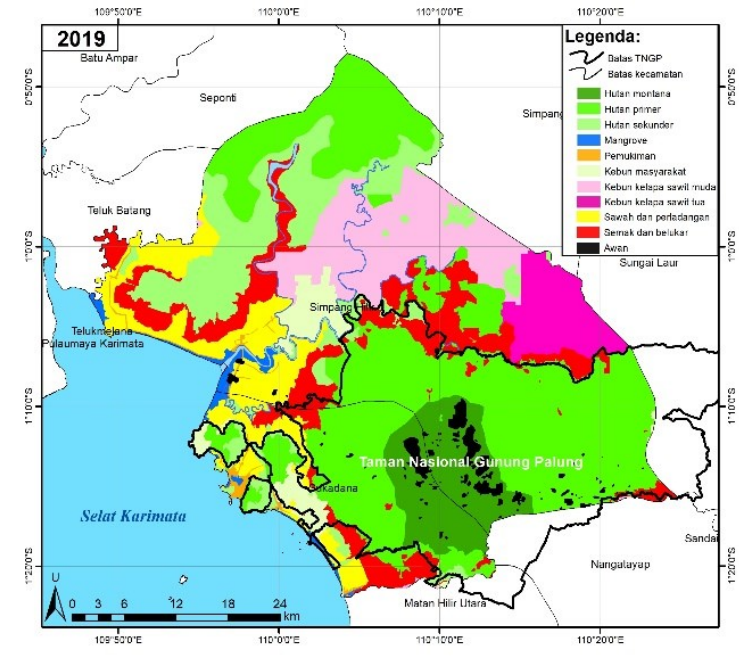

(b)

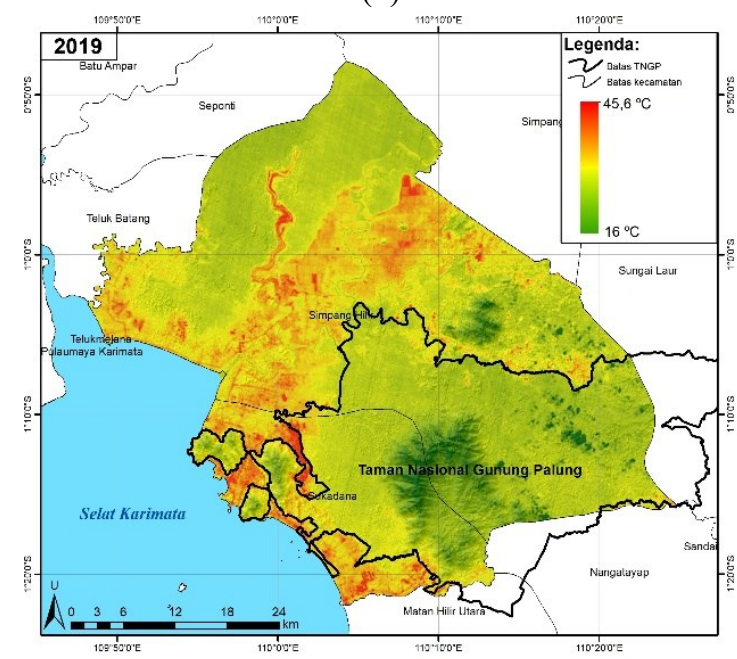

(d)

\section{Gambar 2. Peta Tutupan Lahan (a) Tahun 2018 dan (b) 2019, serta Peta Suhu Permukaan yang Diperoleh dari Analisis Penginderaan Jauh (c) Tahun 2018 dan (d) Tahun 2019}

Gambar 3 menunjukkan intensitas heat island $\left(\mathrm{I}_{\mathrm{HI}}\right)$ tahun 2018 dan 2019. $\mathrm{I}_{\mathrm{HI}}$ rata-rata paling tinggi terdapat pada kawasan permukiman, yakni $1,5 \pm 2,5{ }^{\circ} \mathrm{C}$ di tahun 2018 dan 2,8 $\pm 1,5^{\circ} \mathrm{C}$ di tahun 2019 . Perkebunan kelapa sawit muda memiliki nilai $\mathrm{I}_{\mathrm{HI}}$ rata-rata yang melebihi kawasan $\mathrm{I}_{\mathrm{HI}}$ permukiman ditahun 2018, yakni 2,1 $\pm 1,7{ }^{\circ} \mathrm{C}$. Sedangkan di tahun 2019 mengalami penurunan intensitas hanya $1,7 \pm 1,4{ }^{\circ} \mathrm{C}$. Penurunan nilai $\mathrm{I}_{\mathrm{HI}}$ rata-rata pada perkebunan kelapa sawit disebabkan oleh pertumbuhan kelapa sawit telah menurunkan suhu permukaan (Rushayati et al., 2017). Namun, jika dibandingkan dengan tutupan lahan lainnya, kebun kelapa sawit muda dapat dikatakan telah terjadi heat island. $\mathrm{Hal}$ ini ditandai dengan rata-rata $\mathrm{I}_{\mathrm{HI}}$ yang tinggi dan menyamai kawasan permukiman. Hasil berbeda dengan kebun kelapa sawit tua yang terbentuk cool island dengan suhu lebih 
dingin dari kebun kelapa sawit yang muda. $\mathrm{I}_{\mathrm{HI}}$ pada kelapa sawit tua juga mendekati nilai $\mathrm{I}_{\mathrm{HI}}$ hutan sekunder.

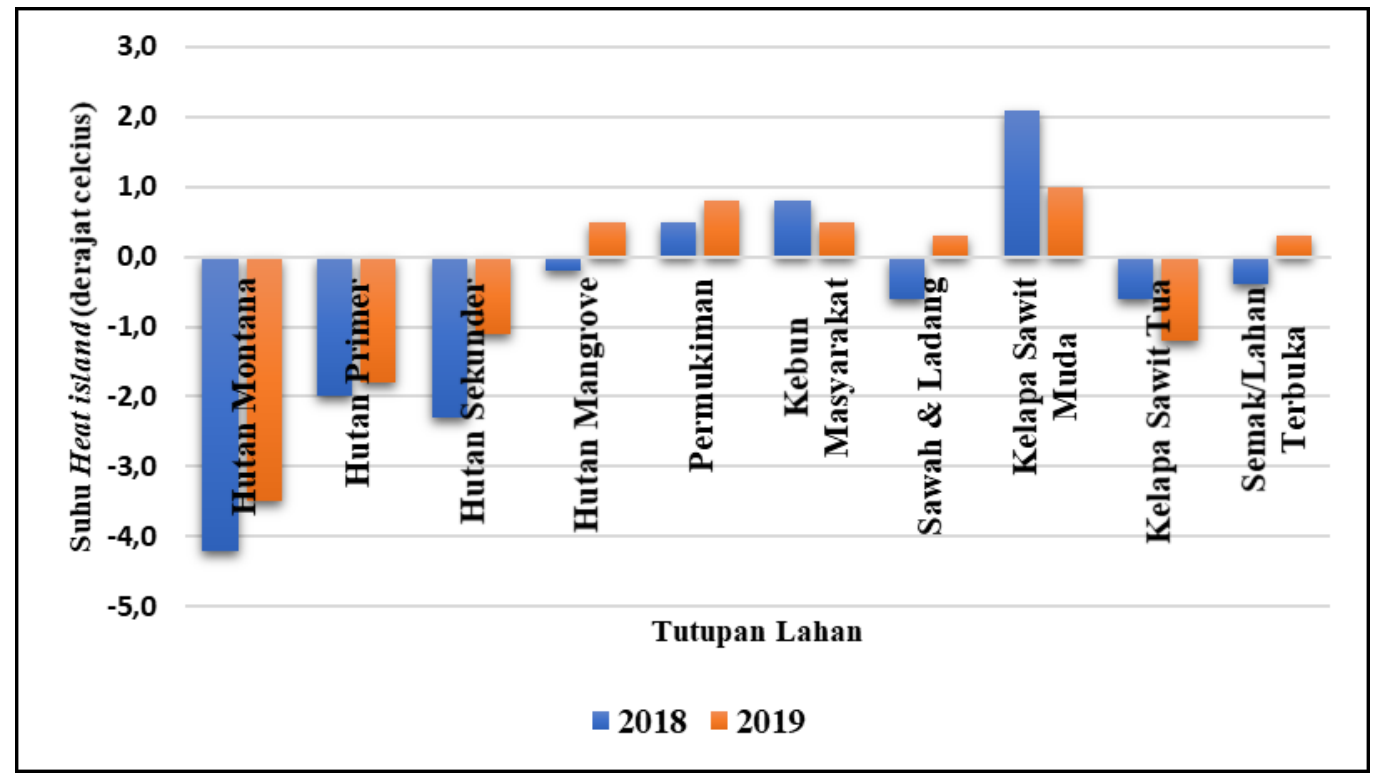

Gambar 3. Grafik intensitas $\left(\mathrm{I}_{H 1}\right)$ dan Perubahan Nilai Suhu Heat /sland rata-rata tiap tutupan lahan, terlihat kelapa sawit muda memiliki rata-rata tertinggi dan menurun $1^{\circ} \mathrm{C}$ dari tahun $2018 \mathrm{ke} 2019$

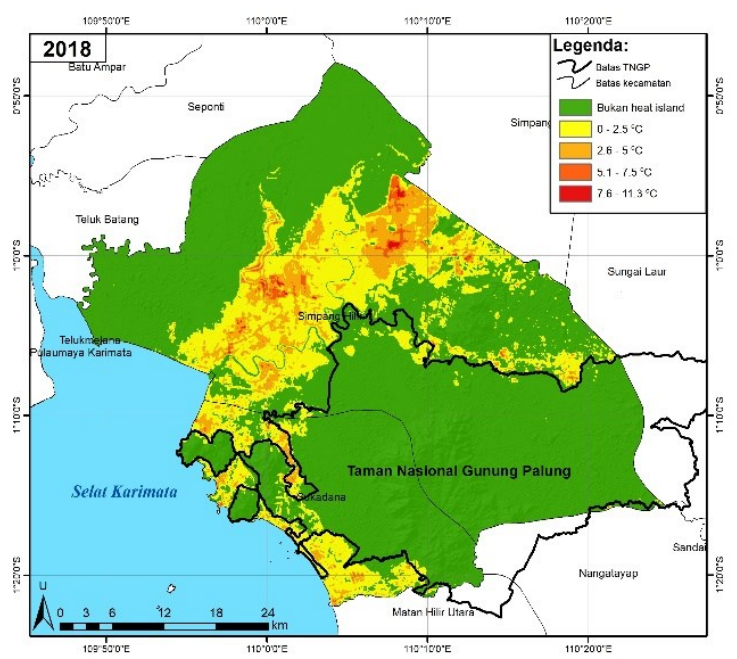

(a)

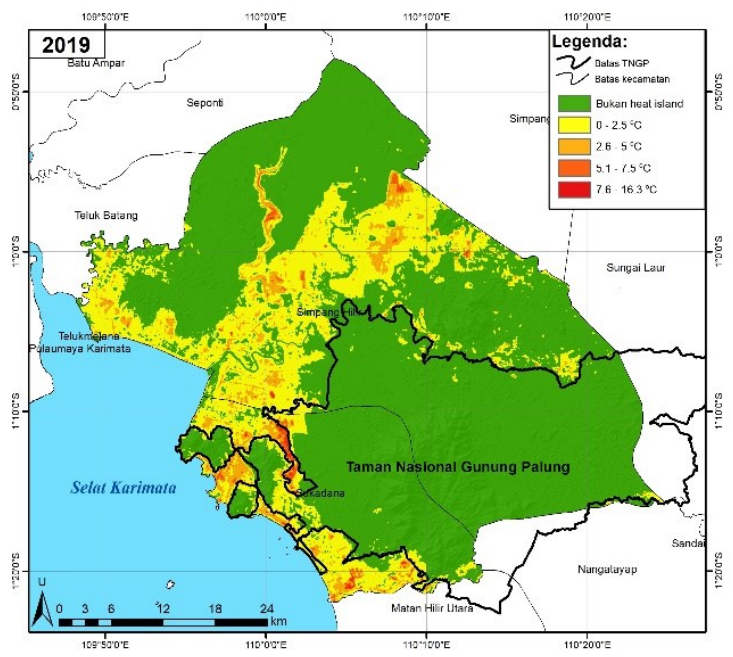

(b)

\section{Gambar 4. Peta Heat Island(a) Tahun 2018 dan (b) Tahun 2019}

Perlu menjadi perhatian bahwa $\Delta \mathrm{T}$ berubah mengikuti nilai suhu permukaan daerah penelitian (Streutker, 2003). Jika analisis dilakukan pada area yang lebih luas atau lebih sempit, maka $\Delta \mathrm{T}$ akan berubah (Fawzi, 2017). Namun, distribusi spasial heat island tetap berada pada suhu yang lebih tinggi (Aris et al., 2019). Peta heat island pada Gambar 4, $\mathrm{I}_{\mathrm{HI}}>$ $5{ }^{\circ} \mathrm{C}$ berada pada area yang sama, yakni berada di perkebunan kelapa sawit muda dan pada area perkotaan Sukadana. Suhu tinggi pada area perkebunan kelapa sawit muda berasosiasi dengan pembukaan lahan baru untuk penanaman kelapa sawit atau kelapa sawit muda yang baru ditanam. Pertumbuhan kelapa sawit tua yang telah berumur $>11$ tahun mampu 
membentuk kanopi yang menurunkan suhu di sekitarnya. Hal ini yang menyebabkan area perkebunan kelapa sawit tua tidak ada efek heat island. Rekomendasi di masa yang akan datang, area penelitian heat island akan terbentuk pada kawasan perkotaan (urban heat island) dan kawasan pertanian atau lahan terbuka. Implikasi dari penelitian penelitian ini adalah dapat mengetahui heat island akibat deforestasi atau perubahan tutupan lahan, terutama pada perkebunan kelapa sawit. Sehingga dapat dilakukan perencanaan dan mitigasi dampak yang ditimbulkan terutama efek terhadap kesehatan manusia (Heaviside et al., 2017).

Perkebunan kelapa sawit memengaruhi iklim lokal pada awal pembukaan lahan dan masa pertumbuhan. Jika telah dewasa, iklim lokal yang awalnya ditandai dengan heat island akan normal kembali dengan menyamai suhu hutan. Hal ini dapat menunjukkan bahwa pada perkebunan sawit, perubahan heat island dipengaruhi oleh usia tanam dari kelapa sawit dengan pendekatan tumbuhan yang lebih tua akan membentuk kanopi dan menurunkan suhu lokal. Dilihat dari sisi lain, konversi menjadi kebun kelapa sawit dapat memengaruhi biodiversitas (Vijay et al., 2016). Penanaman kembali kelapa sawit karena pohon kelapa sawit hanya memiliki umur produksi sampai 25 tahun, akan memulai siklus perubahan iklim lokal lagi menjadi heat island. Hal tersebut tentu akan memengaruhi hilangnya biodiversitas gelombang kedua (Ashton- Butt et al., 2019).

\section{Kesimpulan}

Perkebunan kelapa sawit memiliki intensitas heat island yang berbeda untuk umur yang masih muda dan tua. Heat island terbentuk di kebun kelapa sawit muda dengan nilai $\mathrm{I}_{\mathrm{HI}}$ rata-rata yang melebihi kawasan $\mathrm{I}_{\mathrm{HI}}$ permukiman ditahun 2018 , yakni $2,1 \pm 1,7{ }^{\circ} \mathrm{C}$. sedangkan di tahun 2019 mengalami penurunan intensitas hanya 1,7 $\pm 1,4{ }^{\circ} \mathrm{C}$. Pada kebun kelapa sawit yang telah tua (umur 11-12 tahun), heat island digantikan oleh cool island dengan $\mathrm{I}_{\mathrm{HI}}$ mendekati nilai hutan sekunder. Penurunan ini terjadi seiring dengan pertumbuhan kelapa sawit sehingga diperlukan manajemen penanaman yang baik agar kelapa sawit tidak tumbuh serentak pada kebun yang luas. Proses ini dapat menjadi sebuah mitigasi dampak yang ditimbulkan dari $\mathrm{I}_{\mathrm{HI}}$ yang tinggi. Penelitian ini berimplikasi pada perencanaan wilayah kedepannya terutama pada pemilihan lokasi perkebunan kelapa sawit yang strategis dengan dampak terhadap lingkungan yang minim.

\section{Daftar Pustaka}

Aris, A., Syaf, H., Yusuf, D. N., \& Nurgiantoro. (2019). Analysis of urban heat island intensity using multi temporal landsat data; case study of Kendari City, Indonesia. IOP Conference Series Earth and Environmental Science, 389(1), 1-14. doi:10.1088/1755-1315/389/1/012002.

Ashton- Butt, A., Willcock, S., Purnomo, D., Suhardi, Aryawan, A. A. K., Wahyuningsih, R., Naim, M., Poppy, G. M., Caliman, J., Peh, K. S. - H., \& Snaddon, J. L. (2019). Replanting of first-cycle oil palm results in a second wave of biodiversity loss. Ecology and Evolution, 9(11), 6433-6443. doi:10.1002/ece3.5218.

Barsi, J. (2019). Atmospheric Correction Parameter Calculator. https:/ / atmcorr.gsfc.nasa.gov/.

BPS Kabupaten Kayong Utara. (2018). Statistik daerah Kabupaten Kayong Utara 2018. Badan Pusat Statistik Kabupaten Kayong Utara.

BPS Kabupaten Kayong Utara. (2019). Kabupaten Kayong Utara dalam angka 2019. Badan Pusat Statistik Kabupaten Kayong Utara.

Cai, M., Ren, C., Xu, Y., Lau, K. K.-L., \& Wang, R. (2018). Investigating the relationship between local climate zone and land surface temperature using an improved WUDAPT methodology - A case study of Yangtze River Delta, China. Urban Climate, 24, 485-502. doi:10.1016/j.uclim.2017.05.010.

Coll, C., Galve, J. M., Sánchez, J. M., \& Caselles, V. (2010). Validation of landsat-7/ETM+ thermal-band calibration and atmospheric correction with ground-based measurements. IEEE Transactions on Geoscience and Remote Sensing, 48(1), 547-555. doi:10.1109/TGRS.2009.2024934. 
Curran, L. M., Trigg, S. N., Mcdonald, a K., \& Astiani, D. (2004). Lowland forest loss in protected areas. Terra, 303(February), 1000-1003. doi.org/10.1126/science.1091714.

ESRI. (2016). Zonal Statistics—Help / ArcGIS for Desktop.

http://desktop.arcgis.com/en/arcmap/10.3/tools/spatial-analyst-toolbox/zonal-statistics.htm.

Fawzi, N. I. (2014). Pemetaan emisivitas permukaan menggunakan indeks vegetasi. Majalah Ilmiah Globë, $16(2), 133-140$.

Fawzi, N. I. (2017). Mengukur urban heat island menggunakan penginderaan jauh, kasus di Kota Yogyakarta. Majalah Ilmiah Globë, 19(2), 195-206. doi:10.24895/MIG.2017.19-2.603.

Fawzi, N. I. I., Husna, V. N. N., \& Helms, J. A. A. (2018). Measuring deforestation using remote sensing and its implication for conservation in Gunung Palung National Park, West Kalimantan, Indonesia. IOP Conference Series: Earth and Environmental Science, 149. doi:10.1088/1755-1315/149/1/012038.

Fawzi, N. I., Indrayani, A. M., \& DeKay, K. (2019). Forest change monitoring and environmental impact in Gunung Palung National Park, West Kalimantan, Indonesia. Jurnal Ilmu Lingkungan, 172), 197-204. doi:10.14710/jil.17.2.197-204.

Fawzi, N. I., \& Jatmiko, R. H. (2015). Heat island detection in coal mining areas using multitemporal remote sensing. Proceedings the 36th Asian Conference of Remote Sensing (ACRS 2015), Metro Manila, Philippines.

Gaveau, D. L. A., Locatelli, B., Salim, M. A., Yaen, H., Pacheco, P., \& Sheil, D. (2019). Rise and fall of forest loss and industrial plantations in Borneo (2000-2017). Conservation Letters, 12(3), 1-8. doi:10.1111/conl.12622.

Gronlund, C. J. (2014). Racial and socioeconomic disparities in heat-related health effects and their mechanisms: a review. Current Epidemiology Reports, 1(3), 165-173. doi:10.1007/s40471-014-0014-4.

Hardwick, S. R., Toumi, R., Pfeifer, M., Turner, E. C., Nilus, R., \& Ewers, R. M. (2015). The relationship between leaf area index and microclimate in tropical forest and oil palm plantation: Forest disturbance drives changes in microclimate. Agricultural and Forest Meteorology, 201, 187-195. doi:10.1016/j.agrformet.2014.11.010.

Heaviside, C., Macintyre, H., \& Vardoulakis, S. (2017). The urban heat island: implications for health in a changing environment. Current Environmental Health Reports, 4, 296-305. doi:10.1007/s40572-0170150-3.

Karyono, T. H. (2015). Predicting comfort temperature in Indonesia, an initial step to reduce cooling energy consumption. Buildings, 5(3), 802-813. doi:10.3390/buildings5030802.

Kementerian Lingkungan Hidup dan Kehutanan (KLHK). (2019). Rekapitulasi luas kebakaran hutan dan lahan (ha) per provinsi di Indonesia tahun 2014-2019. Retrieved from http://sipongi.menlhk.go.id/pdf/luas_kebakaran.

Li, G., Zhang, X., Mirzaei, P. A., Zhang, J., \& Zhao, Z. (2018). Urban heat island effect of a typical valley city in China: Responds to the global warming and rapid urbanization. Sustainable Cities and Society, 38, 736745. doi:10.1016/j.scs.2018.01.033.

Li, H., Zhou, Y., Li, X., Meng, L., Wang, X., Wu, S., \& Sodoudi, S. (2018). A new method to quantify surface urban heat island intensity. Science of The Total Environment, 624, 262-272. doi:10.1016/j.scitotenv.2017.11.360.

Lima Alves, E., \& Lopes, A. (2017). The urban heat island effect and the role of vegetation to address the negative impacts of local climate changes in a small Brazilian City. Atmosphere, 8(2), 18. doi:10.3390/atmos8020018.

NASA. (2019). FIRMS - Fire Map. Retrieved from https://firms.modaps.eosdis.nasa.gov/map/\#z:9;c:110.3,1.3;t:adv-points;d:2019-08-02..2019-08-03;l:firms_viirs,firms_modis_a,firms_modis_t.

Ozdemir, H., Unal, A., Kindap, T., Turuncoglu, U. U., Durmusoglu, Z. O., Khan, M., Tayanc, M., \& Karaca, M. (2012). Quantification of the urban heat island under a changing climate over Anatolian Peninsula. Theoretical and Applied Climatology, 108(1-2), 31-38. doi:10.1007/s00704-011-0515-8.

Qaid, A., Bin Lamit, H., Ossen, D. R., \& Raja Shahminan, R. N. (2016). Urban heat island and thermal comfort conditions at micro-climate scale in a tropical planned city. Energy and Buildings, 133, 577-595. doi:10.1016/j.enbuild.2016.10.006.

Ramdani, F., Moffiet, T., \& Hino, M. (2014). Local surface temperature change due to expansion of oil palm plantation in Indonesia. Climatic Change, 123(2), 189-200. doi:10.1007/s10584-013-1045-4. 
Rasul, A., Balzter, H., Smith, C., Remedios, J., Adamu, B., Sobrino, J., Srivanit, M., \& Weng, Q. (2017). A review on remote sensing of urban heat and cool islands. Land, 6(2), 38. doi:10.3390/land6020038.

Risdiyanto, I., Ariyani, W., \& Sujatnika, O. (2019). Regional heat capacity changes on oil palm plantation development in 1994-2010 based on Landsat-5 TM satellite data. IOP Conference Series: Earth and Environmental Science, 336, 012023. doi:10.1088/1755-1315/336/1/012023.

Robock, A. (1991). Surface cooling due to forest fire smoke. Journal of Geophysical Research, 96(D11), 20.86920.878. doi:10.1029/91JD02043.

Rushayati, S. B., Hermawan, R., \& Meilani, R. (2017). Age-surface temperature estimation model: When will oil palm plantation reach the same surface temperature as natural forest? IOP Conference Series: Earth and Environmental Science, 54(1), 012048. doi:10.1088/1755-1315/54/1/012048.

Sabajo, C. R., le Maire, G., June, T., Meijide, A., Roupsard, O., \& Knohl, A. (2017). Expansion of oil palm and other cash crops causes an increase of the land surface temperature in the Jambi province in Indonesia. Biogeosciences, 14(20), 4619-4635. doi:10.5194/bg-14-4619-2017.

Salafsky, N. (1994). Forest gardens in the Gunung Palung region of West Kalimantan, Indonesia. Agroforestry Systems, 28(3), 237-268. doi:10.1007/BF00704759.

Streutker, D. R. (2003). Satellite-measured growth of the urban heat island of Houston, Texas. Remote Sensing of Environment, 85(3), 282-289. doi:10.1016/S0034-4257(03)00007-5.

USDA. (2019). Indonesia oilseeds and products annual 2019. https://www.fas.usda.gov/data/indonesiaoilseeds-and-products-annual-3.

USGS. (2019). Landsat 8 (L8) data users handbook (Version 4). Department of the Interior U.S. Geological Survey. Retrieved from https://landsat.usgs.gov/landsat-8-18-data-users-handbook-section-1.

Valor, E., \& Caselles, V. (1996). Mapping land surface emissivity from NDVI: Application to European, African, and South American areas. Remote Sensing of Environment, 573), 167-184. doi:10.1016/00344257(96)00039-9.

Vijay, V., Pimm, S. L., Jenkins, C. N., \& Smith, S. J. (2016). The impacts of oil palm on recent deforestation and biodiversity loss. PLOS ONE, 11(7), e0159668. doi:10.1371/journal.pone.0159668.

Wang, R., Li, F., Yang, W., \& Zhang, X. (2009). Eco-service enhancement in peri-urban area of coal mining city of Huaibei in East China. Acta Ecologica Sinica, 29(1), 1-6. doi:10.1016/j.chnaes.2009.04.001.

Wilcove, D. S., \& Koh, L. P. (2010). Addressing the threats to biodiversity from oil-palm agriculture. Biodiversity and Conservation, 19(4), 999-1007. doi:10.1007/s10531-009-9760-x.

Yang, Q., Huang, X., \& Tang, Q. (2019). The footprint of urban heat island effect in 302 Chinese cities: Temporal trends and associated factors. Science of the Total Environment, 655, 652-662. doi:10.1016/j.scitotenv.2018.11.171.

Zhou, D., Xiao, J., Bonafoni, S., Berger, C., Deilami, K., Zhou, Y., Frolking, S., Yao, R., Qiao, Z., \& Sobrino, J. (2018). Satellite remote sensing of surface urban heat islands: Progress, challenges, and perspectives. Remote Sensing, 11(1), 48. doi:10.3390/rs11010048. 